\title{
Co-existence and collaboration: Australian AIDS quilts in public museums and community collections
}

\author{
Tuan Nguyen*
}

\begin{abstract}
The Australian AIDS Memorial Quilt is arguably the most recognizable artefact of the AIDS Crisis in Australia. Consisting of over 800 panels, most of the quilt is now divided between a public museum (Museum of Applied Arts and Sciences, Sydney) and a community organization (AIDS Memorial Candlelight Vigil \& Quilt Project, Melbourne). This paper compares the accessibility and meaning of the quilt depending on its location. In doing so, it argues that neither is a 'better' custodian for these objects as their differences are also the source of their unique contribution to the care and interpretation of the quilts. The tensions that exist between museums and LGBTIQ communities were exposed when the proper residence of one of the panels was disputed. I use this case to suggest that equitable collaboration can only occur if museums take more cues from communities.
\end{abstract}

Key words: LGBTIQ, queer, collaboration, Australia, AIDS, quilt

\begin{abstract}
Introduction
The AIDS Crisis was one of the defining events of the 1980s that sent shockwaves throughout the countries that it ravaged, particularly among gay men, haemophiliacs, injecting drug users and sex workers. In an effort to memorialize those who died and to influence responses to the disease, AIDS quilt projects started in dozens of places around the world. Created in community contexts, some have found their way into public museum collections. ${ }^{1}$ This paper will compare the accessibility and meaning of the Australian AIDS Memorial Quilt (AAMQ) depending on its location. The AAMQ is unusual in that most of it is housed in both a public museum (Museum of Applied Arts and Sciences, Sydney) and a community collection (AIDS Memorial Candlelight Vigil \& Quilt Project, Melbourne [Victorian Quilt Project]), allowing the implications for the quilts to be contrasted. Starting with the history of AIDS quilts, I will then outline why the AAMQ came to be divided between a public museum and community organization. The effect of its separation in terms of access and meaning will then be considered. Finally, negotiations that occurred after the Victorian Quilt Project requested the transfer of one of the quilt panels exposed tensions that continue to exist between museums and LGBTIQ or queer communities. ${ }^{2}$ In looking at the borders that exist between each as they come into contact, I argue that equitable collaboration can only occur if museums take more cues from communities. Thereafter, the unique contribution of each domain to the care and interpretation of the quilts might be harnessed.
\end{abstract}

\section{The history of AIDS quilts}

AIDS quilts, though often displayed together to appear as a single patchwork quilt, are comprised of individual panels. The panel in Fig. 1, for example, commemorates Tony Guthrie and was made by his friends. It depicts Guthrie in the centre of a baroque oval frame surrounded by tools he used as a hairdresser and makeup artist. With camp humour, it incorporates Barbie accessories including a hairdryer, combs, mirrors and hair rollers; on a sash is written playful 


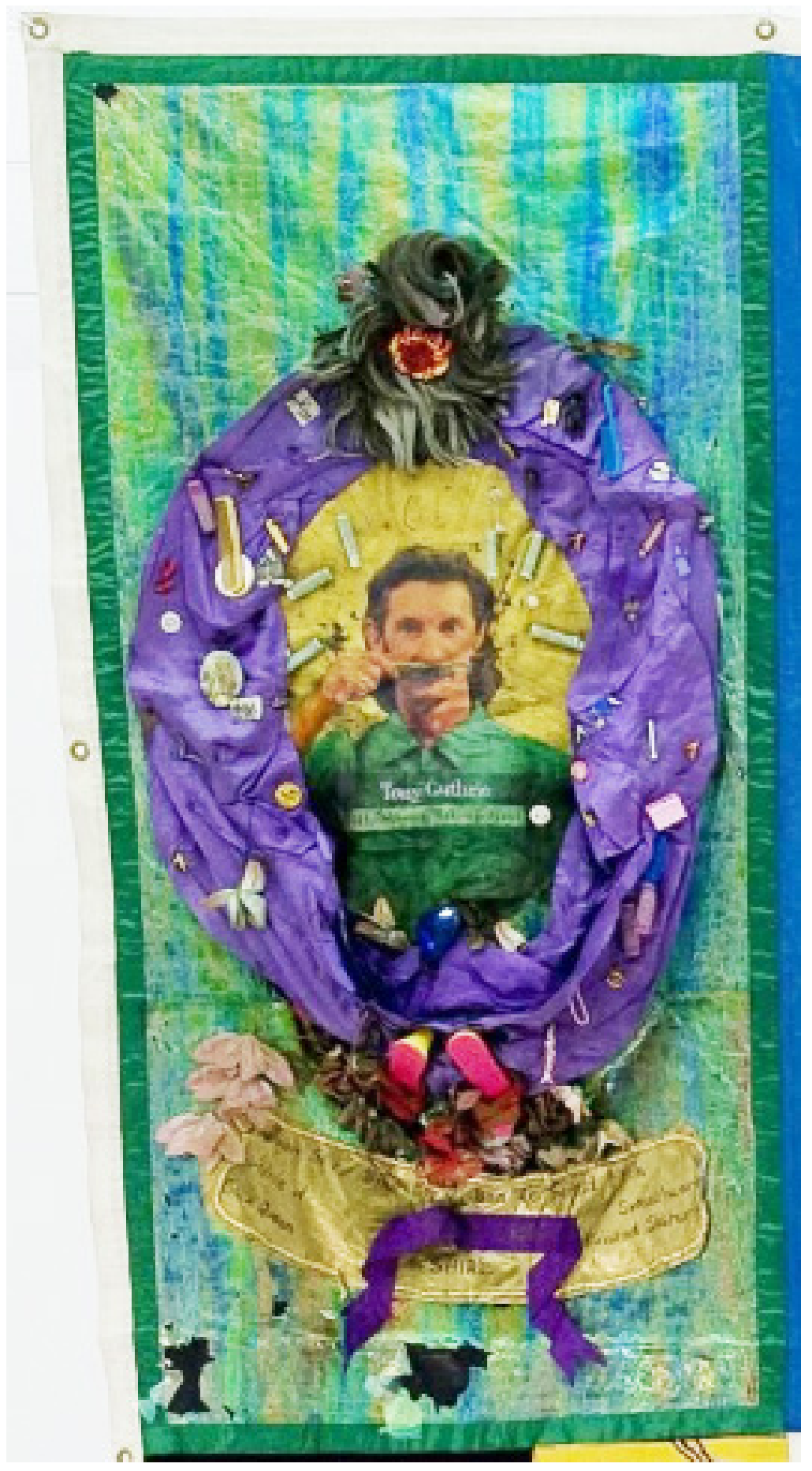

Fig. 1. Tony Guthrie's quilt panel. Source: Museum of Applied Arts and Sciences 
sentiments from his friends such as '[f]abulous girlfriend' and '[m]oody, difficult bitch' (Yardley et al. 1994: 112). Each $180 \mathrm{~cm}$ by $90 \mathrm{~cm}$ panel, deliberately the size of a burial plot, represents someone who has died of complications from AIDS. Like Guthrie's panel, they typically display the name, and a tableau of images and objects that represent the deceased. However, many are anonymous given the compound stigma of homosexuality, AIDS, illicit drug use and sex worker phobia (though clearly not all applied to every HIV-positive person). Individual panels would be stitched into a 'block' of eight panels. These would, in turn, be laid out at convention centres, town halls and fields in spectacular displays of mourning and commemoration (Fig. 2).

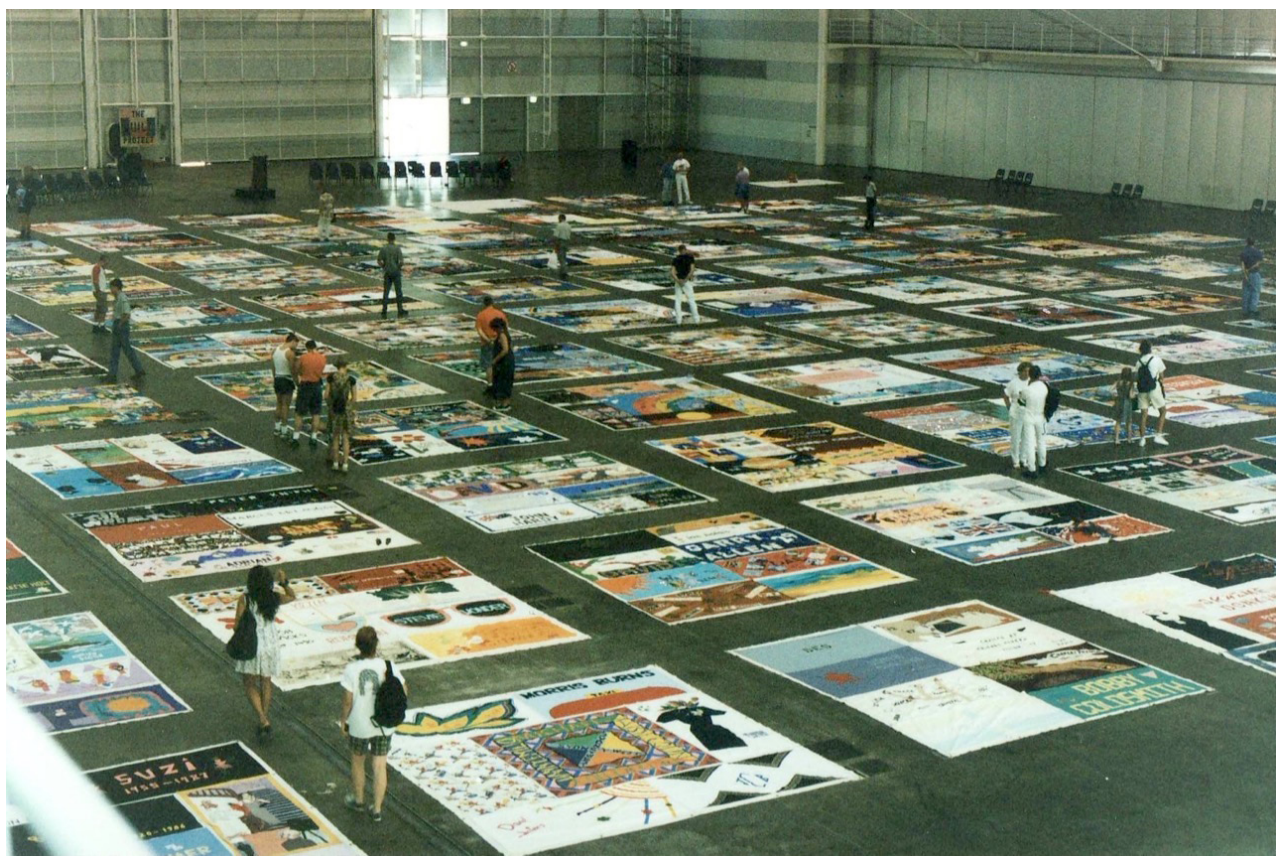

Fig. 2. Display of the $A A M Q$ at the Sydney Convention and Exhibition Centre. Source: Mannie De Saxe

AIDS quilts are arguably the most recognizable material culture from the HIVIAIDS epidemic in the places they were produced and displayed. The condition that would come to be known as AIDS was first clinically observed in 1981 in the United States, with the first case of AIDS in Australia detected the following year. In San Francisco in 1985, Cleve Jones asked participants in a march to write the names of someone they knew who had died of complications from AIDS on poster boards. Wanting to continue the effort to oppose the anonymity of those who had died, Jones stitched the first panel of the NAMES Project AIDS Memorial Quilt (NAMES Project) in February 1987. By August, there were 400 panels representing a small fraction of the 13,329 recorded deaths in the United States (Hawkins 1996: 137). The NAMES Project now includes over 48,000 panels. ${ }^{3}$

Seeing the NAMES Project quilts in 1987 inspired Andrew Carter and Richard Johnson to start the AAMQ in September 1988. The AAMQ had four aims:

1. To provide a positive and creative means of expression for those whose lives have been touched by the HIVIAIDS epidemic, and to facilitate the grieving process.

2. To encourage support for people living with HIVIAIDS and their families, friends and lovers.

3. To illustrate the impact of the HIVIAIDS epidemic by showing the humanity behind the statistics. 
4. To promote a compassionate and educational dialogue, reduce HIVIAIDS related discrimination, and to provide support for preventative education (Yardley et al. 1994: 7).

Like the NAMES Project, the AAMQ conveys the enormity of loss fromAIDS. Elizabeth Woodhams reflects, '[t]here were 44 panels when it was first unfolded in 1988. When I later succeeded Andrew Carter as National Convener of the Australian AIDS Quilt Project there were 72 panels and some 500 when I left the Quilt Project in 1991' (Woodhams 2004: 144-5). Now numbering over 800, the panels represent a fraction of the 9,900-11,000 deaths recorded in Australia. ${ }^{4}$

The passionate adoption of quilt projects worldwide-inspired by the NAMES Project but with no formal connection-reveals not only the depth of emotion surrounding the issue, but also something of the affective qualities of quilts. Cleve Jones, founder of the NAMES Project, recalls the emotional associations when he first thought to use the medium:

I was flooded with memories of home and family and the warmth of a quilt....At the time, HIV was seen as the product of aggressive gay male sexuality, and it seemed that the homey image and familial associations of a warm quilt would counter that (Jones 2000: 107-8).

Quilts projects tapped the above meanings to humanize people with AIDS for those who knew little about the disease except through sensationalist media. Their ability to nurture empathy and provide a space for grieving led to ambivalence among activists. Douglas Crimp, an AIDS activist and cultural critic, questioned if attention to the quilt was to assuage the guilt of people who had done little in practical terms to help those affected, sanitize gay culture by veiling it in ordinariness and, more darkly, provide 'stunning evidence of the mass death of gay men' (Crimp 2002: 198-201). A similar critique was mounted by many members of ACT UP_-the AIDS Coalition to Unleash Power-who viewed quilt projects and candlelight vigils as a distraction from the immediate task of caring for the living and preventing new infections (Gould 2009: 223-33). Phil Carswell, one of the founding members and inaugural President of the Victorian AIDS Council (VAC) in Australia, has a different view. For him, memorials attracted people who would not attend any other AIDS events (Power 2011: 151). In addition, they were great tools of advocacy as '[y] ou could take a Quilt panel to a public event and immediately have people on side' (152). It is telling that a large portion of the AAMQ is housed at VAC, showing that emotion and politics, and grief and the drive to effect change, are not mutually exclusive.

\section{Quilts at the Museum of Applied Arts and Sciences (MAAS)}

Unlike in the USA, the Australian federal government was quick to respond to the epidemic. A bipartisan response was initiated by the Hawke Labor Government and involved a coalition of medical professionals, AIDS councils which received money to educate and care for the communities most affected by the epidemic, and a general awareness campaign that educated the broader public about the threat posed by the virus. The first Australian death resulting from AIDS occurred in July 1984; in November the same year, the federal government established bodies to coordinate its response to the epidemic. Measures such as widespread education, the introduction of needle and syringe programmes, the promotion of condom use and the provision of antiretroviral medication under Medicare meant that AIDS diagnoses peaked in 1994. ${ }^{5}$

From the mid-1990s, being HIV-positive for many people in higher-income countries became a manageable long-term condition due to the availability of effective antiretroviral medications. It also meant that few new quilts were being added to the Sydney Quilt Project in the 2000s. Recognizing the shift, the convener Philip Diment approached MAAS in Sydney to house the quilt. After a five-year process of research and documentation, the museum acquired 97 blocks of the AAMQ in 2011. As part of the process, blocks with links to Victoria were transferred to the Victorian Quilt Project. Accessioning the objects into the museum and subjecting them to the processes of conservation, research, storage and registration changed their relationship to communities. Since MAAS was established in 1879, its collection practices have evolved to incorporate both historical concerns for comprehensive description and more 
contemporary concerns with significance. The database entry for the panel in Fig. 1 gives the simple description, '[t]he quilt is a square shape, constructed with eight joined panels edged with canvas,' alongside the detailed statement of significance placing the object in the social and political context of the AIDS Crisis. ${ }^{6}$ It is now standard practice for such documentation and research to occur before acquisition, explaining why it took five years in the case of the quilt. Custom storage requiring a $\$ 90,000$ contribution from the Sydney Quilt Project was also developed to house the blocks (Fig. 3). ${ }^{7}$ The AAMQ collection is now housed in a purpose built museum storage facility; each block is stored on a separate tray; it is wrapped in conservationgrade inert materials; and foam rollers are used to ensure that hard folds do not occur. The result accords with the idea that museum collections are 'a permanent repository, a great barrel of amber in which things—once dropped—will be forever preserved' (Weil 1997: 3).

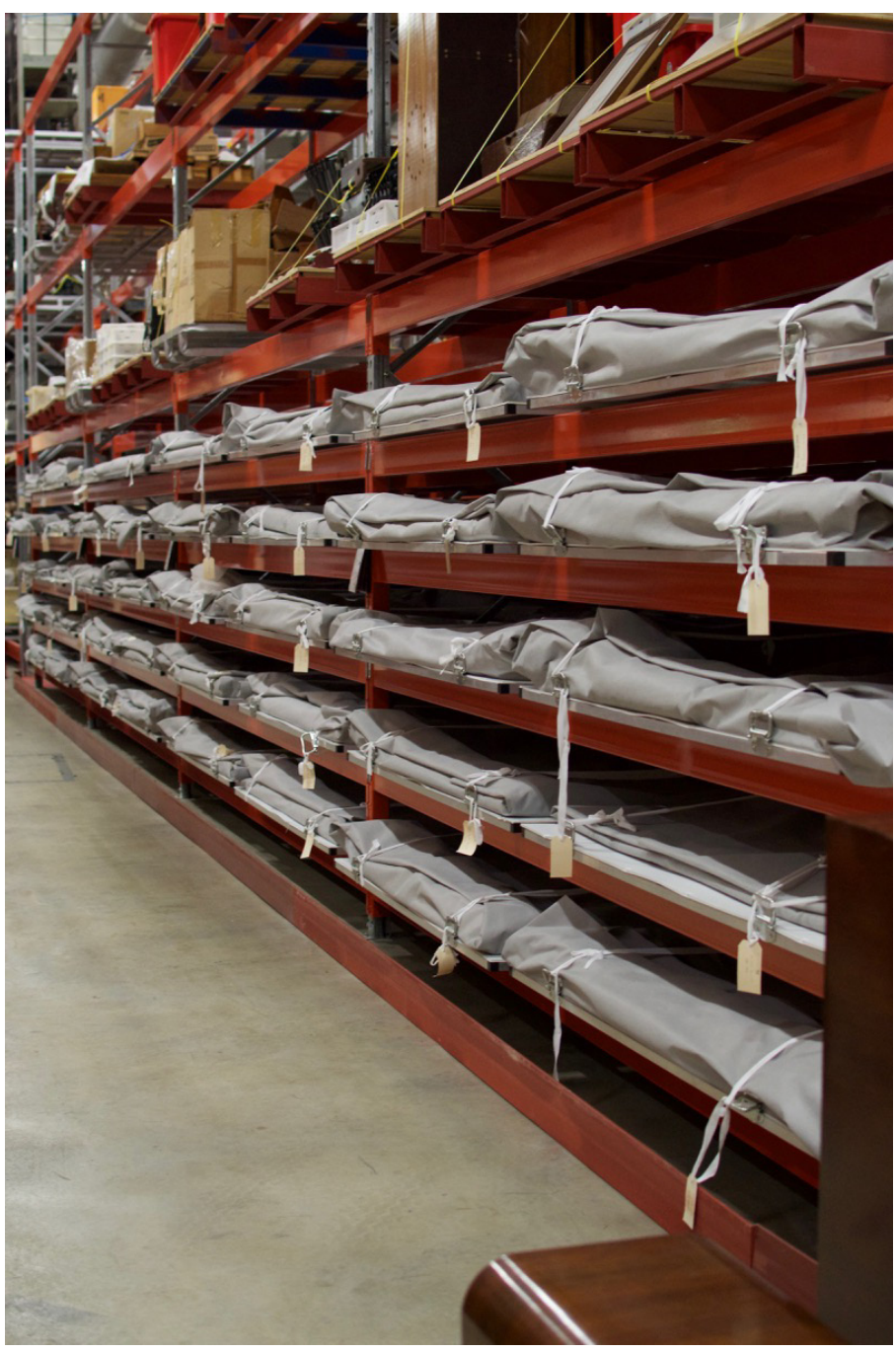

Fig. 3. Quilt storage shelves at MAAS. Source: Tuan Nguyen
Since going to MAAS, the quilts have been used in a number of exhibitions. In 2010, a block of the quilt was displayed in the exhibition 80 s Are Back to illustrate the history of the AIDS $\mathrm{Cr}$ isis during the decade. In 2012, another block was featured at the entrance to the exhibition HIV and AIDS 30 Years On: The Australian Story. The museum leant a block to St Vincent's Hospital in 2014 to commemorate 30 years since it opened the first dedicated HIVIAIDS ward in Australia. ${ }^{8}$ Images of the quilt were projected prominently on the façade of Hamer Hall, Melbourne, to greet delegates to the $20^{\text {th }}$ International AIDS Conference. ${ }^{9}$ Finally, sections of the quilt have been displayed annually for World AIDS Day. These displays show that although the quilts have been removed from their original context, they are regularly used to represent the human impact of HIV/ AIDS forgeneral museum audiences, often by weaving the subject into wider narratives (e.g. the exhibition 80s Are Back). 


\section{Quilts at the AIDS Memorial Candlelight Vigil \& Quilt Project (Victorian Quilt Project)}

The quilts managed by the Victorian Quilt Project continue to be managed by a volunteer committee which makes it available for safe sex education workshops, displays and community events; the committee also organizes the annual candlelight vigil (Fig. 4). These interrelated events seek to commemorate those who have died, and to promote continued support for those living with HIV. The first candlelight memorial was held in 1985 when two people stood in the City Square, Melbourne. By 1989, attendance increased to 300 and included the unfolding of one quilt block. Participation increased again the following year to a crowd of 4,000 who viewed the unfolding of 100 panels (Melbourne AIDS Memorial Candlelight Vigil Committee 1992). The quilts continue to be used in a similar manner and for a broad range of events. As well as organizing events for World AIDS Day on the $1^{\text {st }}$ December, the committee has made blocks available for displays coinciding with the Midsumma Festival (an annual LGBTIQ cultural festival based in Melbourne).

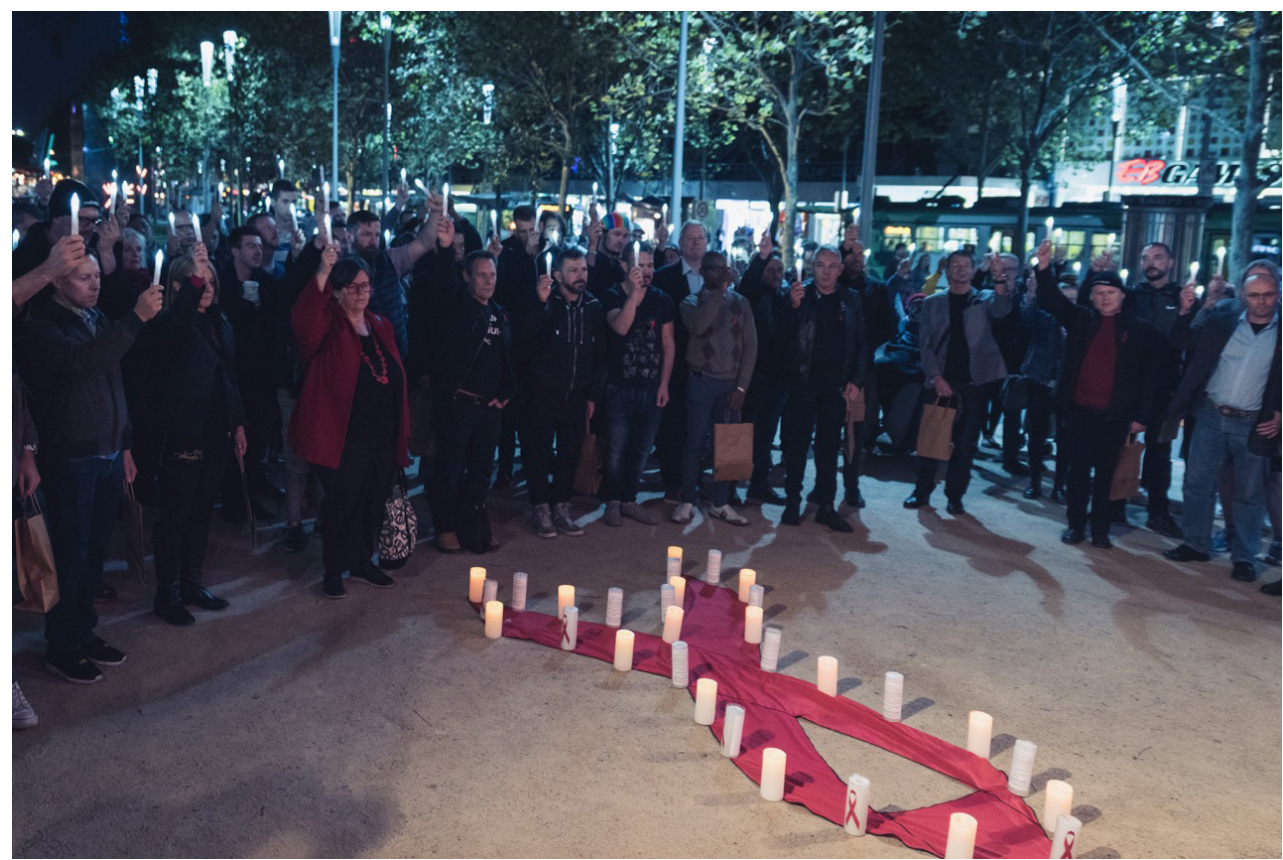

Fig. 4. 2016 candlelight memorial in Melbourne. Source: Living Positive Victoria \& Daniel Burke Photography

The Victorian quilts remain close to the communities in which they were created. They are managed and primarily viewed by the friends, families and lovers of those who have died. In contrast, quilts at MAAS are mostly viewed by those more distant from LGBTIQ communities. Furthermore, given their museum setting, they are further removed from the continuing public health responses to HIV. It is telling that the Victorian quilts are housed within space donated by the Victorian AIDS Council (VAC), an organization with a mission to reduce HIV transmissions and promote the health of those living with HIV. A significant part of the success of Australia's response to the epidemic was due to the use of the social networks and cultural registers of the communities affected. Formed in 1983, the VAC was a product of this approach. ${ }^{10}$ Indeed, the early management included many 1970s gay liberation activists meaning 'you almost had a straight transposition of the gay liberation in 1973 to an AIDS Council' (David Herkt cited in Robinson 2014: 97-8). The quilts share an overlapping history with the VAC and are bound to the same communities. 
Remaining in the community context in which they were made, the quilts are stored in a markedly different way than those at MAAS. The 'permanent repository...great barrel of amber' approach does not apply here. While the quilts are lovingly handled, their pristine conservation is not the primary objective. The founder of the NAMES Project, Cleve Jones, recounted that 'I always wanted the panels laid out flat on the ground so people could touch them' (Jones 2000: xi). The quilts at MAAS are not laid on the ground nor are visitors allowed to handle them. For the exhibition Absolutely Mardi Gras: Costumes and Design of the Sydney Lesbian and Gay Mardi Gras, the museum recognized that visitors who were close to the creators of the costumes might want to touch them. Conservators made a particular effort to 'allow close access to the costumes without endangering the costumes to handling' (Gissing 1997-1998: 47). 'Endangering' reveals the museum's overriding duty of care towards its collection. While understandably conserving the object for future as well as present communities, the strict conditions placed on quilts at MAAS did not apply in their original context.

Venues available to community groups often cannot meet the expected environmental conditions for museum collection items (Fig. 5). Moreover, the quilts were often made by those inexperienced at quilting using variety of techniques including patchwork, appliqué, painting and incorporation of objects which makes them difficult to conserve. Even many small, volunteerrun or non-metropolitan museums cannot provide the lighting and display conditions, and extensive temperature and humidity logs that large museums set as prerequisites for loans. In addition, conditions placed on the display of fabrics tend to be more stringent as they are prone to fading. As a consequence, compared to quilts controlled by community-based organizations like the NAMES Project and the Victorian Quilt Project, 'museums in Australia and New Zealand seem to be less eager for the quilt blocks to travel around the country' (Mensch and Wildt 2014: 97). This has led a committee member of the Victorian Quilt Project, Gordon Wilson, to advise, 'I would seriously consider [not] giving any NAMES Project Quilts

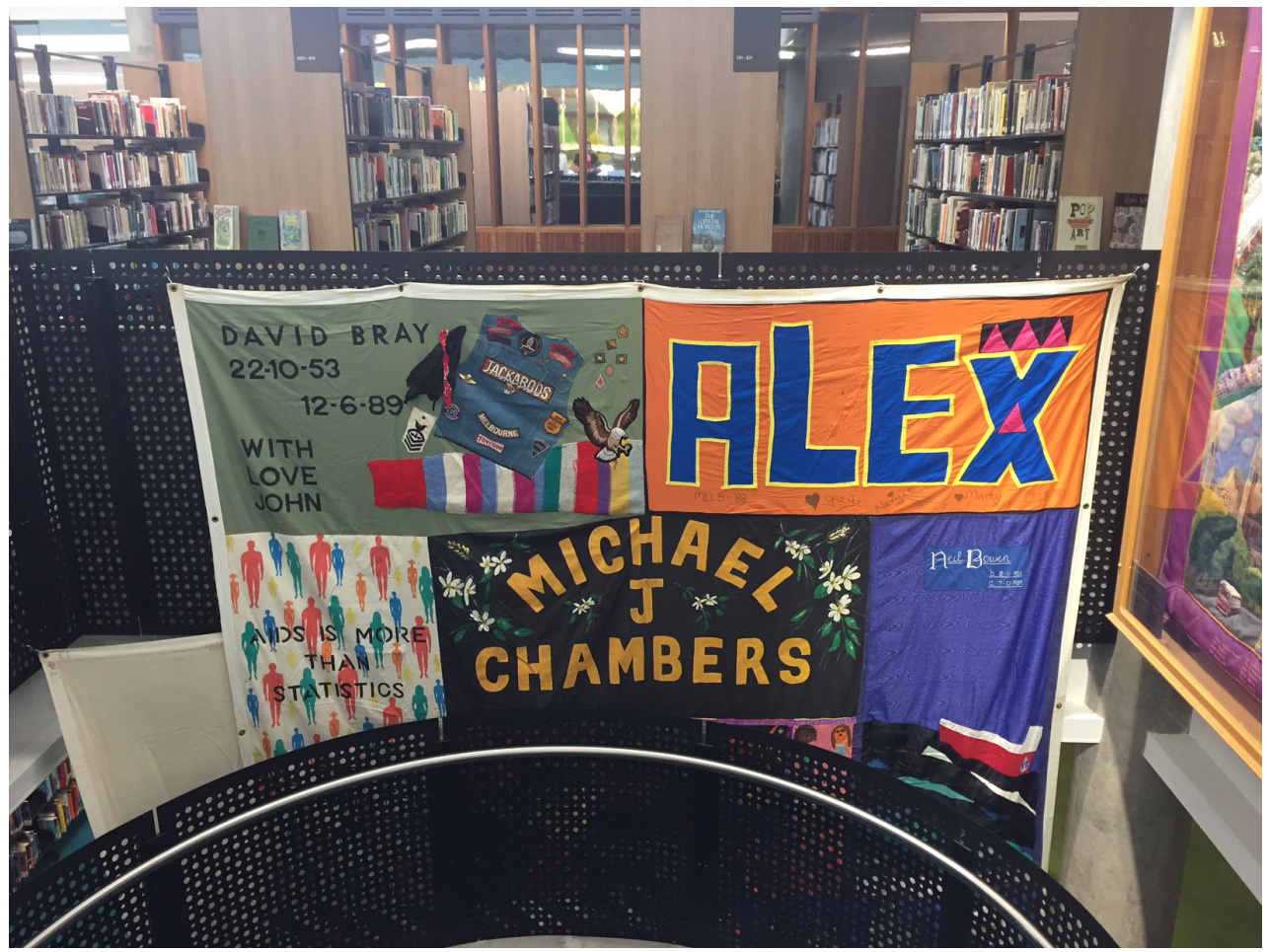

Fig. 5. Block lent to Bendigo Library. Source: John Hall. 
that you have to a museum...to be able to take them out as necessary and put on show' (98). Terry Thorley, the former national convener of the AAMQ, agrees that the ability for LGBTIQ communities to use the quilt is crucial: 'if we just created a quilt that was static, that would defeat the purpose..... It's the ability then to take the quilt back into the community...to use it to support safe sex education. That's very important' (as cited in Power 2011: 150). Beyond the community, the AAMQ helped to promote compassion for those living with HIVIAIDS and provided a focal point for politicians to announce their support for tackling the epidemic. Hence, the cofounder of the AAMQ Andrew Carter was able to read out a letter of support for the quilt from the Prime Minister Bob Hawke when a portion was displayed at the $5^{\text {th }}$ International Congress on AIDS in 1989. ${ }^{11}$

However, quilts managed by source communities are not necessarily more accessible. For one, as has been noted above, MAAS aims to represent and appeal to the breadth of social diversity. If accessibility is considered from this standpoint, the museum is making the quilt more accessible to groups beyond LGBTIQ communities both current and future. From another perspective, quilts managed by communities present other accessibility issues. While MAAS only displays a limited number of blocks for temporary exhibitions and World AIDS Day, all 97 quilt blocks can be viewed online at any time. The AAMQ website-www.aidsquilt.org. au - used to contain a searchable database but now the website consists of a single landing page with broken hyperlinks and the search function has been unavailable for several years. Issues of sustainability often affect community initiatives given their comparative lack of resources and vulnerability to collapse when key driving members move on. Evidently, key differences exist between museums and LGBTIQ communities, between MAAS and the Victorian Quilt Project, in their management of the AAMQ. Nevertheless, neither is a 'better' custodian of the quilts. Rather, the ways in which they diverge contribute different qualities to the interpretation of the AIDS quilts. At the same time, their divergences are sources of tension when the two organizations come in contact.

\section{Exposed tensions}

It is not often that the tensions between museums and LGBTIQ communities are expressed explicitly. However, they were exposed when the Victorian Quilt Project requested that MAAS transfer custodianship of one of the blocks to them. Again, a block is a unit containing eight quilt panels and, as part of the process of accessioning the quilts into the MAAS collection, blocks with predominate links to Victoria were transferred to the Victorian Quilt Project. There were several blocks with links to both Victoria and Sydney that remained in contention, including block number 103 that contained Daren Olver's panel (Fig. 6). Cheryl and Alvie Olver-who signed the panel 'with our love, Mum [and] Dad'-would come to displays of the quilts in Melbourne and were saddened by its absence. The convener of the Victorian Quilt Project, Doris Beecher, requested the block be returned by the museum. John Hall from the VAC, which stores the Victorian quilts, was brought into the negotiations after Beecher's requests were unsuccessful. He recalls:

Doris would ring the Powerhouse Museum [the main site of MAAS] and they would end up hanging up on her because she was a nuisance. She wanted to get something back from the museum. She probably used the wrong words, wrong language, wrong approach, doesn't matter. They'd all be running for cover.... I came up to have a meeting with them and they said 'no, it's an artefact' and I said 'we use it.' They were horrified because we use it. These panels are handled, they're on display, they're transported by loved ones of the person who died. This is not a museum piece yet. I said 'one day, I hope it will be. It's not yet. We'll happily hand it back to you when the epidemic is over.' We had a meeting. They said 'no, no, no, no, no'; they were horrified that we use them in such a way and that they weren't in a climate controlled room, light controlled room. No, it's a living document, I kept saying 'it's a living document, it's a living testimony to things lived.' We were coming from very different angles. ${ }^{12}$ 


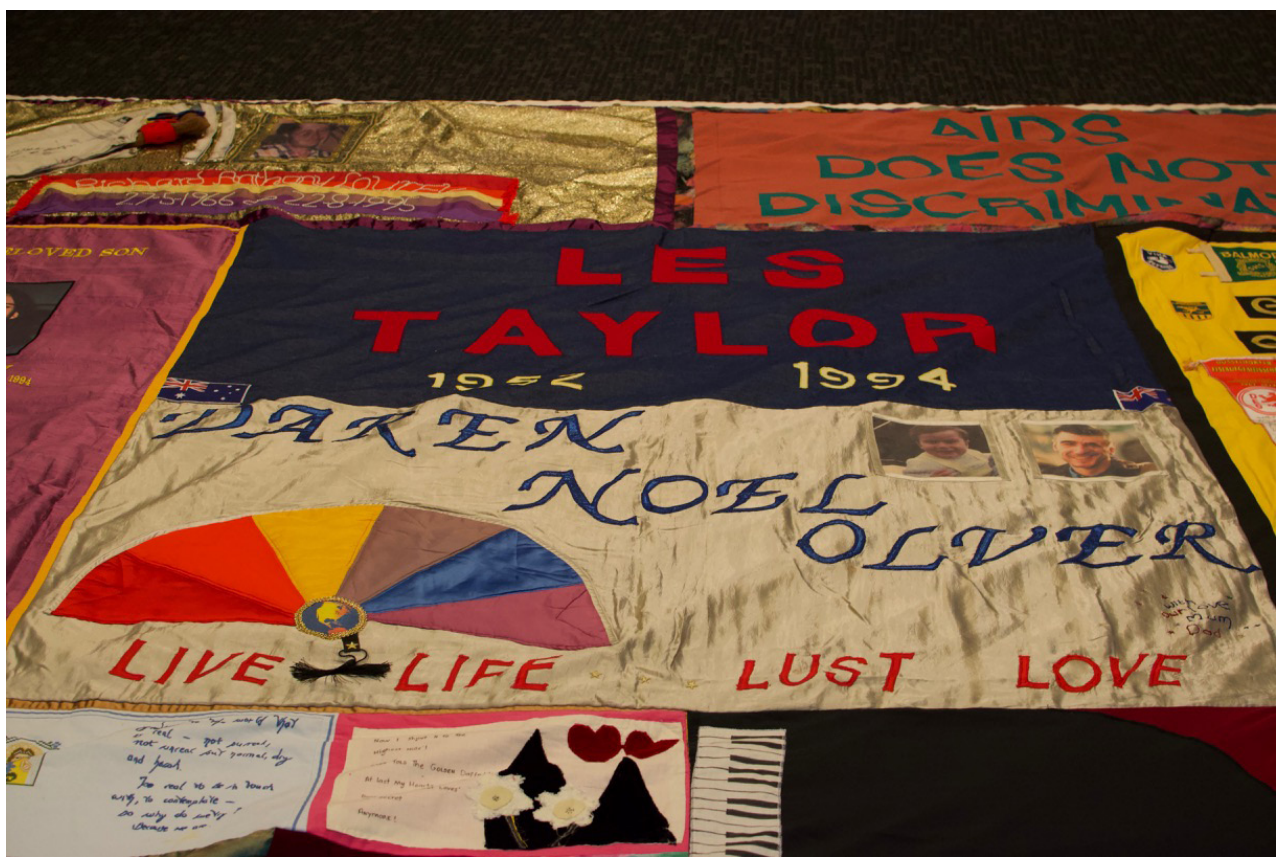

Fig. 6. Daren Olver's panel. Source: Tuan Nguyen

Speaking to both Hall and representatives of MAAS, there is a clear mismatch in recollections of the meetings. Instead of attempting to reconcile the details of their accounts, I will attempt to interpret them on their own terms, taking into account the differing perspectives they represent. From my doctoral study on queer inclusion in Australian museums, I have observed that despite only mounting several exhibitions relevant to LGBTIQ communities, MAAS has arguably done more than any large, public Australian museum in terms of queer inclusion. ${ }^{13}$ It further has developed a significant collection of costumes and posters from the Sydney Gay and Lesbian Mardi Gras, medical collections relating to the HIVIAIDS response, and a large portion of the AAMQ. Hall's comments might be taken as a critique of museums in general rather than MAAS in particular.

Hall saying 'this is not a museum piece yet....We'll happily hand it back to you when the epidemic is over' conveys that he sees value in museums, but this value is one of reflecting on the past. As AIDS quilts still comfort those who created them and they still have a role in advocacy and education, Hall believes they should remain within LGBTIQ communities. Many within museums want to shift his perspective by insisting that museums can have contemporary relevance and maintain active relationships with communities. In terms of AIDS quilts, community-based organizations that have retained management of them have done exceptional work in weaving objects into the life of their communities. Public museums, however, have a responsibility towards a broader set of relations. If the benchmark is ongoing connection with source communities, then retention by communities is 'better.' If longevity (physical and organizational), integration with broader social narratives, and size of audiences are used as the markers of success, then location within public institutions is 'better.' Each has differing effects for the 'general public' (that has been implicitly imagined as heterosexual) and queer counterpublics, a public with 'an awareness of its subordinate status' (Warner 2005: 56).

\section{Co-existence and collaboration}

Mensch and Wildt (2014: 103) write about a similar case in the Netherlands where the NAMEN Project (NAMES Project) approached the Amsterdam Museum to house its quilts, two of which 
were accepted. The authors advocate for 'shared ownership' of the quilts and shared authority over decisions relating to their selection, documentation, conservation and presentation (105). It is a familiar argument within museums where conclusions often lead to recommendations for more collaboration, co-creation, shared ownership, shared authority or 'contact zone' relations (Clifford 1999; Frisch 1990; Simon 2010). They arguably still assume that museums will be key (and perhaps primary) players in heritage decision-making and do not countenance that their participation might not be welcomed. Even widely held understandings of curatorship continue to hold that 'the curator as scholar, expert on the collections and knowledgeable about the relevant discipline...led the project, chose the objects for display and decided on what to say in the text panels and labels' (Hooper-Greenhill 2000: 133). Instead of retreading the familiar path of calling for a sharing of authority, I question whether the terms of this discourse are enough to shift the imbalance of power between museums and communities.

Relating the above supposition to the idea of the museum as a 'contact zone,' Boast (2011) similarly questions why museum scholars have often underplayed the inherent asymmetry in exchanges between museums and communities. The notion of the 'contact zone' was applied to the museum context in the influential article 'Museums as Contact Zones' (Clifford 1999). Using examples of engagements between public institutions and Indigenous peoples, Clifford suggests that museums can become 'centers... cross[ed] by objects and makers' (445). That is, instead of maintaining its historical position at the centre of authority, museums might engage in contact relations with source communities in order to redress historical inequalities. Clifford does acknowledge that these negotiations occur in conditions of deep-seated inequality and that '[i]t may, indeed, be utopian to imagine museums as public spaces of collaboration, shared control, complex translation and honest disagreement' (448). Boast (2011) characterizes the way that the 'contact zone' has been taken up by museums since Clifford's writings as a 'neocolonial genre,' a way of re-appropriating the contact zone as 'a site in and for the center.... The key problem, as I see it, lies deeper-deep in the assumptions and practices that constitute the museum in the past and today' (67). In the case of LGBTIQ communities, for instance, the assumptions and practices that attend heteronormativity remain largely unchallenged in museums (Sandell and Frost 2010: 170-1).

It is unsurprising that museum scholars and practitioners privilege museums in their analyses, ready to argue for their contribution to society and the need for their ongoing support. In the area of LGBTIQ public history, such a focus may underplay the role of community organizations in the preservation of their own heritage. In my research on queer inclusion in Australian museums, I have adopted the term 'queer community heritage organizations' (QCHOs) to describe these organizations, similar to 'community-based heritage organizations' used elsewhere (Keith 2012). Most QCHOs have been started in Australia and overseas since the 1970s, coinciding with the gay liberation movement, the rise of new social history and later the new museology. They would change how history was written and communicated, with history from below and from the margins gaining new prominence. The Australian Lesbian and Gay Archives (ALGA), established in 1978, is the largest QCHO in Australia (Fig. 7). As well as developing the largest repository of LGBTIQ historical material in Australia, it has produced or contributed to more queer exhibitions than any public institution in Australia. Many QCHOs like ALGA appropriate and adapt gallery, library, archive and museum practices, illustrating that '[i]n practice distinctions between community archives... and museums... or indeed between community libraries... are not at all precise nor necessarily very useful' (Flinn and Stevens 2009: 5-6). Similar to QCHOs, the AAMQ and its state chapters were engaged in cultural advocacy at a time when support from cultural institutions was not as forthcoming. However, the last ten years has seen increasing interest from public museums to represent LGBTIQ communities, alongside the growth of 'queer museology' to inform these efforts. ${ }^{14}$ In exchanges between museums and communities, the former should acknowledge the foundational work of QCHOs in preserving queer history. While, in some cases like the Sydney quilts of the AAMQ, museums may be invited to become custodians of community collections, in others they will play a supporting role. Equitable engagements require museums to take more cues from communities, whether that means that QCHOs choose to co-exist and collaborate with museums, transfer their collections to them or, indeed, choose not to engage. 


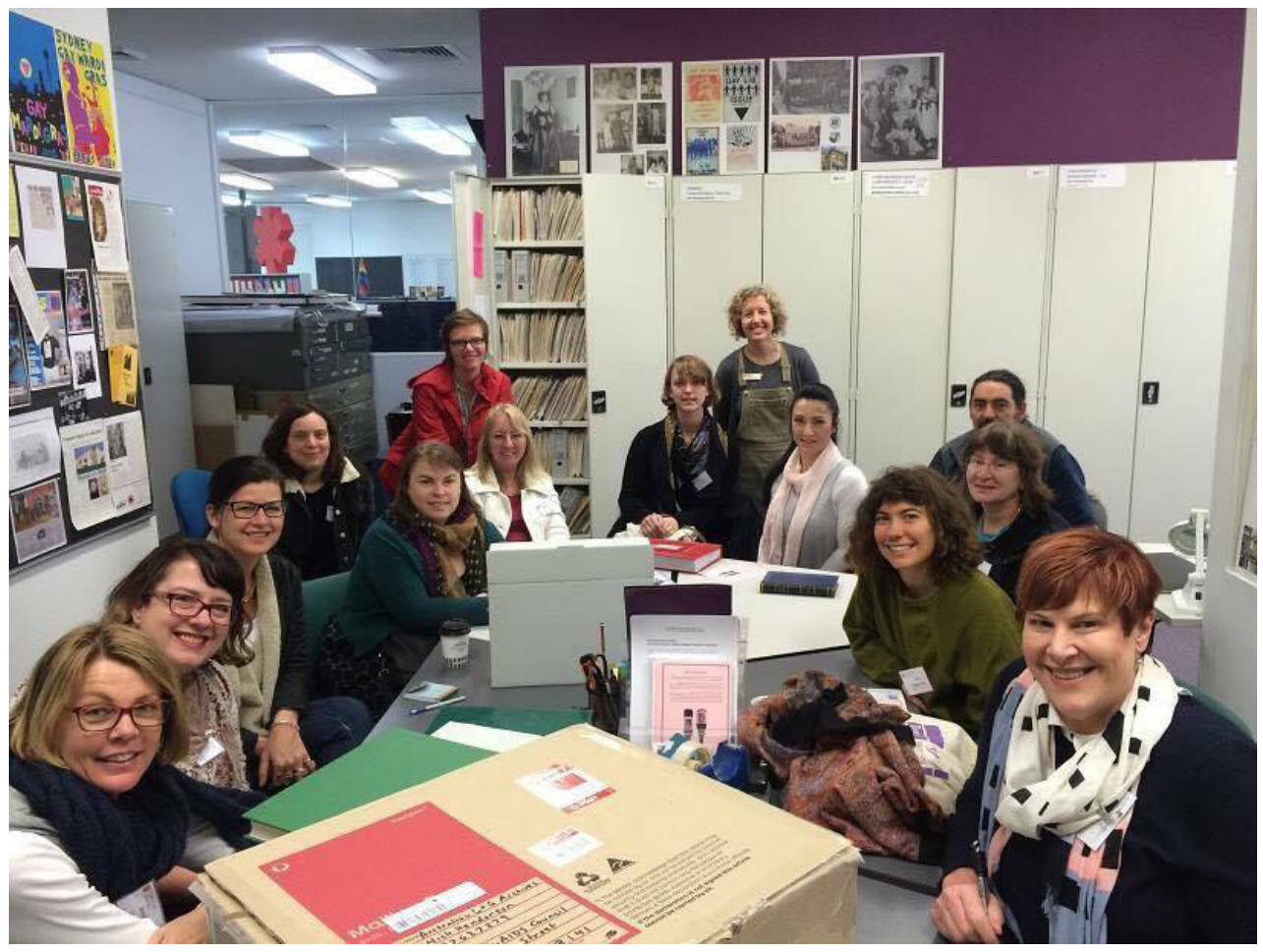

Fig. 7. Volunteers at ALGA. Source: Australian Lesbian and Gay Archives

\section{Conclusion}

'Will [young people] remember the Quilt when—oh wonderful day-it's packed off to a museum?' - Cleve Jones (2000: xii), founder of the NAMES Project AIDS Memorial Quilt.

The Australian AIDS Memorial Quilt has not been wholly packed off to a museum but neither has it remained solely within its community of origin. Its divided location allowed for the implications for collections in community versus public museum contexts to be compared. The management of the Australian quilts now forms another patchwork of sorts, with the diversity of the stories they represent now reflected in the diversity of their management. The difference between the care and interpretation of the AAMQ at the Museum of Applied Arts and Sciences and the Victorian Quilt Project is also the source of their unique contributions: museums offer a broader audience, greater resources, and organizational and object permanence; and queer community heritage organizations maintain connections between the quilt and those closest to them. Both are concerned with promoting understanding and compassion around HIVIAIDS but their advocacy reaches different but overlapping audiences; then, as well as now, AIDS quilts are calls to action and reflection. It would, in my view, be a wonderful day when museums and queer communities could collaborate to combine their unique strengths, requiring museums to take more cues from communities. The case of the Olver panel, however, showed that the duty of care of museums to its collections could be at odds with how communities use the same objects. More than a case of mutual misunderstanding, the case shows that museums often approach community engagements from a position of power. In pointing out these asymmetric relationships, I walk a fine line-at once personal, political and professional-in wanting to recognize the difficulties my museum colleagues have in re-orienting their organizations towards communities, at the same time as honoring the communities that sustain me. It can 
be done but only painstakingly, one patch at a time, never with uniformity. The outcome will be complex, like the texture of queer heritage.

Received: 6 January 2017

Finally Accepted: 26 March 2018

\section{Notes}

1 Public museums that have accessioned AIDS quilts include the Museum of Applied Arts and Sciences (discussed in this article), Newcastle Museum in Australia, Museum of New Zealand Te Papa Tongarewa, and Amsterdam Museum in the Netherlands (Buckley et al. 2013).

2 I use 'queer' both as an umbrella term that includes but is not limited to LGBTIQ (lesbian, gay, bisexual, transgender, intersex, queer) and that also draws upon the conceptual tools developed in queer theory and queer activism. On the latter, resistance to heteronormativity is central, that is, 'the institutions, structures of understanding, and practical orientations that make heterosexuality seem not only coherent - that is, organized as a sexuality - but also privileged' (Berlant and Warner 2005: 309).

3 The NAMES Project Foundation (2016) 'The AIDS Memorial Quilt'. http://www.aidsquilt. org/about/the-aids-memorial-quilt, accessed 12 October 2016.

4 Kirby Institute (2014) 'HIV in Australia: Annual Surveillance Report 2014 Supplement'. https://kirby.unsw.edu.au/sites/default/files/hiv/resources/HIVASRsuppl2014_online.pdf, accessed 23 March 2016.

5 Australian Federation of AIDS Organisations (2015a) 'HIV and Australia: A Short History'. http://www.afao.org.au/library/topic/government/background-briefing-short-history February-2015.pdf, accessed 22 March 2016; Bowtell, W. (2005) 'Australia's Responses to HIVIAIDS 1982-2005'. http://www.lowyinstitute.org/files/pubfiles/Bowtell,_Australia's_ Response_to_HIV_AIDS_logo.pdf, accessed 23 March 2016.

6 Museum of Applied Arts and Sciences (2011) '2011/109/65'. https://ma.as/396761, accessed 2 November 2016.

7 Dunkin, A. (2012) 'AIDS Quilt Convenor Honoured', Gay News Network. http:// gaynewsnetwork.com.au/feature/aids-quilt-convenor-honoured-7128.html, accessed 9 November 2016.

8 Busby, C. (2014) 'Ward 17 South Commemorates 30 Years of HIV Care', Gay News Network. http://gaynewsnetwork.com.au/feature/commemorating-30-years-of-australias-first-hiv-aids-unit-ward-17-south-15766.html, accessed 3 November 2016.

9 YEAH (2014) 'YEAH AIDS 2014 Stop Motion Projection Images on Hamer Hall'. http:// www.redaware.org.au/video-gallery-2/yeah-aids-2014-stop-motion-projection/, accessed 3 November 2016.

10 VictorianAIDS Council and Gay Men's Health Centre (2013) 'OnAustralian Shores', in Under the Red Ribbon: Thirty Years of the Victorian AIDS Council / Gay Men's Health Centre. http://undertheredribbon.com.au/our-story/1983-1987/on-australian-shores/, accessed 2 December 2016.

11 New Zealand AIDS Memorial Quilt Project (2018a) 'Andrew Carter'. http://www.aidsquilt. org.nz/pages/panels/033.html, accessed 28 January 2018.

12 Hall, J. (2015) interview by author, digital recording, 4 March 2015, Melbourne, Victorian AIDS Council. 
13 My forthcoming PhD thesis Queering Australian Museums: Management, Collections, Exhibitions, and Connections addresses the question 'how can LGBTIQ or queer communities be further included in Australian museums on their own terms?' It looks at four areas of museums to consider barriers to and enablers of queer inclusion.

14 'Queer museology' is an area of literature concerned with how LGBTIQ and queer communities might utilize museums and their practices to fulfil their cultural needs. In doing so, it presents ways that museums might be fundamentally reimagined or 'queered.' Most significant monographs, edited volumes and journal issues have been produced in the last ten years which include: Where is Queer? [journal issue] (Fraser and Heimlich 2008); Gender, Sexuality, and Museums: A Routledge Reader (Levin 2010); Interpreting LGBT History at Museums and Historic Sites (Ferentinos 2015); Sex Museums: The Politics and Performance of Display (Tyburczy 2015); LGBTQ America: A Theme Study of Lesbian, Gay, Bisexual, Transgender, and Queer History (Springate 2016); and Museums, Moralities and Human Rights (Sandell 2017).

\section{References}

Berlant, L. and Warner, M. (2005) 'Sex in Public', in Michael Warner (ed) Publics and Counterpublics, 187-208, New York: Zone Books.

Boast, R. (2011) 'Neocolonial Collaboration: Museum as Contact Zone Revisited', Museum Anthropology, 34 (1) 56-70.

Buckley, L., Gasparotti, V. and Kapteijns, N. (2013) An International View of Accessioning and Displaying AIDS Memorial Quilts [unpublished].

Clifford, J. (1999) 'Museums as Contact Zones', in Jessica Evans and David Boswell (eds) Representing the Nation: A Reader: Histories, Heritage and Museums, 435-57, London: Routledge.

Crimp, D. (2002) 'The Spectacle of Mourning', in Melancholia and Moralism: Essays on AIDS and Queer Politics, 195-202, Cambridge, Massachusetts: MIT Press.

Ferentinos, S. (2015) Interpreting LGBT History at Museums and Historic Sites, Lanham: Rowman \& Littlefield.

Flinn, A. and Stevens, M. (2009) "It is Noh Mistri, Wi Mekin Histri." Telling Our Own Story: Independent and Community Archives in the UK, Challenging and Subverting the Mainstream', in Jeannette A. Bastian and Ben Alexander (eds) Community Archives: The Shaping of Memory, 3-27, London: Facet Publishing.

Fraser, J. and Heimlich, J. E. (2008) 'Where Is Queer?' [issue], Museums \& Social Issues: A Journal of Reflective Discourse, 3 (1).

Frisch, M. (1990) 'Introduction', in A Shared Authority: Essays on the Craft and Meaning of Oral and Public History, xv-xxiv, Albany: State University of New York Press.

Gissing, M. (1997-1998) 'Absolutely Mardi Gras: From a One Night Stand to an Exhibition', AlCCM Bulletin, 22/23, 40-9.

Gould, D. B. (2009) Moving Politics: Emotion and ACT UP's Fight against AIDS, Chicago: The University of Chicago Press.

Hawkins, P. S. (1996) 'Naming Names: The Art of Memory and the NAMES Project AIDS Quilt', in Reesa Greenberg, Bruce W. Ferguson and Sandy Nairne (eds) Thinking about Exhibitions, 133-56, London: Routledge. 
Hooper-Greenhill, E. (2000) Museums and the Interpretation of Visual Culture, London: Routledge.

Jones, C. (2000) Stitching a Revolution: The Making of an Activist, San Francisco: HarperSanFrancisco.

Keith, K. F. (2012) 'Moving beyond the Mainstream: Insight into the Relationship between Community-Based Heritage Organizations and the Museum', in Richard Sandell and Eithne Nightingale (eds) Museums, Equality and Social Justice, 45-58, Abingdon, Oxon: Routledge.

Levin, A. K. (ed) (2010) Gender, Sexuality, and Museums: A Routledge Reader, Milton Park, Abingdon, Oxon: Routledge.

Melbourne AIDS Memorial Candlelight Vigil Committee (1992) Remember Their Names, Melbourne: 1992 Melbourne AIDS Memorial Candlelight Vigil Committee.

Mensch, L. M.-V. and Wildt, A. d. (2014) 'AIDS Memorial Quilts: From Mourning and Activism to Heritage Objects', in Sophie Elpers and Anna Palm (eds) Die Musealisierung der Gegenwart: Von Grenzen und Chancen des Sammelns in Kulturhistorischen Museen, 87-106, Bielefeld: Transcript.

Power, J. (2011) Movement, Knowledge, Emotion: Gay Activism and HIVIAIDS in Australia, Canberra: ANU E Press.

Robinson, S. (2014) 'Beyond Tombstones and Grim Reapers: The Gay Community's Challenge to Official HIVIAIDS Campaigns in 1980s Australia and Britain', in Lisa Featherstone, Rebecca Jennings and Robert Reynolds (eds) Acts of Love and Lust: Sexuality in Australia from 1945-2010, 95-111, Newcastle upon Tyne: Cambridge Scholars Publishing.

Sandell, R. (2017) Museums, Moralities and Human Rights, London: Routledge.

Sandell, R. and Frost, S. (2010) 'A Persistent Prejudice', in Fiona Cameron and Lynda Kelly (eds) Hot Topics, Public Culture, Museums, 150-74, Newcastle: Cambridge Scholars.

Simon, N. (2010) The Participatory Museum, Santa Cruz, California: Museum 2.0.

Springate, M. E. (ed) (2016) LGBTQ America: A Theme Study of Lesbian, Gay, Bisexual, Transgender, and Queer History, Washington, DC: National Park Foundation.

Tyburczy, J. (2015) Sex Museums: The Politics and Performance of Display, Chicago: The University of Chicago Press.

Warner, M. (2005) 'Public and Private', in Michael Warner (ed) Publics and Counterpublics, 21-64, New York: Zone Books.

Weil, S. E. (1997) 'Introduction', in Stephen E. Weil (ed) A Deaccession Reader, 1-10, Washington, DC: American Association of Museums.

Woodhams, E. J. D. (2004) Memories Are Not Silence: The Trauma of Witnessing and Art Making. A Phenomenological Exploration of My Lived Experience As An Artist (Doctor of Philosophy), Queensland University of Technology.

Yardley, A., Langley, K. and Hawkes, P. (1994) Unfolding: The Story of the Australian and New Zealand AIDS Quilt Projects, Ringwood, Victoria: McPhee Gribble. 
* Tuan Nguyen is a museum researcher and professional driven to enabling diverse communities to access empowering museum experiences. His forthcoming PhD thesis Queering Australian Museums: Management, Collections, Exhibitions, and Connections (University of Sydney 2018) considers barriers and enablers of further LGBTIQ inclusion in Australian museums. It contributes new case studies to community-oriented museum studies and the emerging field of queer museology. In addition, he has published on topics including mediating conflict surrounding queer content in museum exhibitions (Historic Environment, 2016). You can follow his work at www.vutuannguyen.com

Tuan Nguyen

NSW

Australia

Email: me@vutuannguyen.com 